\title{
A industrialização como vetor de desenvolvimento: a produção do espaço na Microrregião de Marechal Cândido Rondon
}

\author{
Industrialization as a development vector: the production \\ of space in the Micro region of Marechal Cândido Rondon \\ (Paraná, Brazil)
}

\section{La industrialización como un vector de desarrollo: la producción del espacio en la microregión de Marechal Cándido Rondon (Paraná, Brasil)}

\author{
Edson Belo Clemente de Souza \\ ebelo2003@yahoo.com.br \\ Universidade Estadual do Oeste do Paraná
}

\begin{abstract}
Resumo: O presente artigo objetiva analisar a relação de interdependência existente entre os municípios da microrregião de Marechal Cândido Rondon (MCR)/PR (Brasil), dimensionando especialmente o processo industrial e sua relação com o espaço e o território. A escolha da microrregião de Marechal Cândido Rondon - formada pelos municípios de Marechal Cândido Rondon (MCR), Entre Rios do Oeste (ERO), Pato Bragado (PB), Quatro Pontes (QP) e Mercedes (M) - deve-se ao seu contexto histórico e econômico, que está relacionado à construção da Hidrelétrica da Itaipu Binacional (anos 1970) e à faixa de fronteira do Brasil com o Paraguai. Metodologicamente, a presente análise abrange uma revisão da literatura sobre a indústria, numa perspectiva de que a indústria e o espaço (e o território) estão interligados. Além da base teórica para a pesquisa, é relevante a análise de dados fornecidos pelo IBGE, pelo Ipardes e por outros indexadores de órgãos institucionais do Brasil e do Paraguai. A relação do setor industrial com setores a montante, matéria-prima disponível e, a jusante, economia de aglomeração que proporciona suporte ao desenvolvimento industrial, dinamiza a economia da microrregião de $\mathrm{MCR}$, atraindo mão de obra e gerando renda aos municípios.
\end{abstract}

Palavras-chave: Industrialização. Desenvolvimento regional. Microrregião de Marechal Cândido Rondon.

Abstract: This paper aims to analyze the interdependence between the cities of the micro region of Marechal Cândido Rondon (MCR)/PR (Brazil), especially by scaling the manufacturing process and its relation to space and territory. The choice of the micro region of Marecal Candido Rondon (MCR) - which is formed by the towns of MCR, Entre Rios do Oeste (ERO), Pato Bragado (PB), Quatro Pontes (QP) and Mercedes $(\mathrm{M})$ - is due to the historical and economical context of the formation and reality of this micro region, which is related to the construction of the Itaipu Binational Dam (1970's) and to the border region between Brazil and Paraguay. Methodologically, this analysis encompasses a review of the literature about the industry, from the perspective that 
industry and space (and territory) are interrelated. Besides the theoretical basis for the research, we also consider the analysis of data provided by the IBGE (Brazilian Institute of Geography and Statistics), by the Ipardes (Institute of Economic and Social Development of Paraná) and by other indexers of institutional bodies of Brazil and Paraguay. The relationship of industry sector with upstream, available raw material, and the downstream, economy of agglomeration (which provides support to industrial development), boosts the economy of the micro region of MCR, attracting workforce and generating income to the towns.

Keywords: Industrialization. Regional development. Micro region of Marechal Cândido Rondon.

Resumen: Em este artículo se pretende analizar la relación de la interdependencia entre los municipios de la microrregión de Marechal Cándido Rondon (MCR) / PR (Brasil), sobre todo la ampliación del proceso industrial y su relación con el espacio y el territorio. La elección de de la microrregión de Marechal Cândido Rondon - formada por los municípios de Rondón (MCR), Entre Ríos do Oeste (ERO), Pato Bragado (PP), Cuatro Puentes (QP) y Mercedes (M) se debe a su contexto económico y histórico, que está relacionado con la construcción de la Hidroeléctrica de Itaipú Binacional (1970) y la fronteriza de la región entre Brasil y Paraguay. Metodológicamente el presente análisis incluye una revisión de la literatura sobre la industria a partir de la perspectiva de interconexión de la industria y el espacio (y el territorio). Además de la base teórica de la investigación es relevante para el análisis los datos proporcionados por el IBGE, por lo IPARDES y por otros organismos institucionales de Brasil y Paraguay. La relación con el sector industrial, con sectores la montante, materia prima disponible, y, la jusente, economía de aglomeración que proporciona soporte al desarrollo de la industria, dinamiza la economía de la microrregión de MCR, atrayendo mano de obra y generando renta para los municipios.

Palabras claves: Industrialización. Desarrollo Regional. Microrregión de Marechal Cândido Rondon.

\section{INTRODUÇÃO}

O presente artigo tem como objetivo analisar a relação de interdependência entre os municípios da microrregião ${ }^{1}$ de Marechal Cândido Rondon (MCR) da qual fazem parte MCR, Entre Rios do Oeste (ERO), Pato Bragado (PB), Quatro Pontes (QP) e Mercedes (M), (Mapa 1), dimensionando especialmente o processo industrial e sua relação com o espaço e o território. Todos esses municípios estão inseridos na Mesorregião Oeste Paranaense.

O município de MCR exerce uma polarização em relação aos demais municípios, sobretudo em relação ao setor industrial, na perspectiva de que o espaço microrregional atrai mão de obra e gera renda aos municípios.

1 O termo Microrregião Geográfica é utilizado pelo Instituto Brasileiro de Geografia e Estatística (IBGE) para a destinação de estatísticas e formulação e monitoramento de políticas públicas. Conforme o IBGE (2004), trata-se de um recorte territorial constituído por um "conjunto de municípios, contíguos e contidos na mesma unidade de federação, definidos com base em características do quadro natural, da organização da produção e de sua integração". Nesta pesquisa, porém, alerta-se que a espacialidade sugerida pelo termo microrregião não se coaduna com a espacialidade proposta pelo IBGE. 
Mapa 1 - Localização dos municípios da Microrregião de Marechal Cândido Rondon
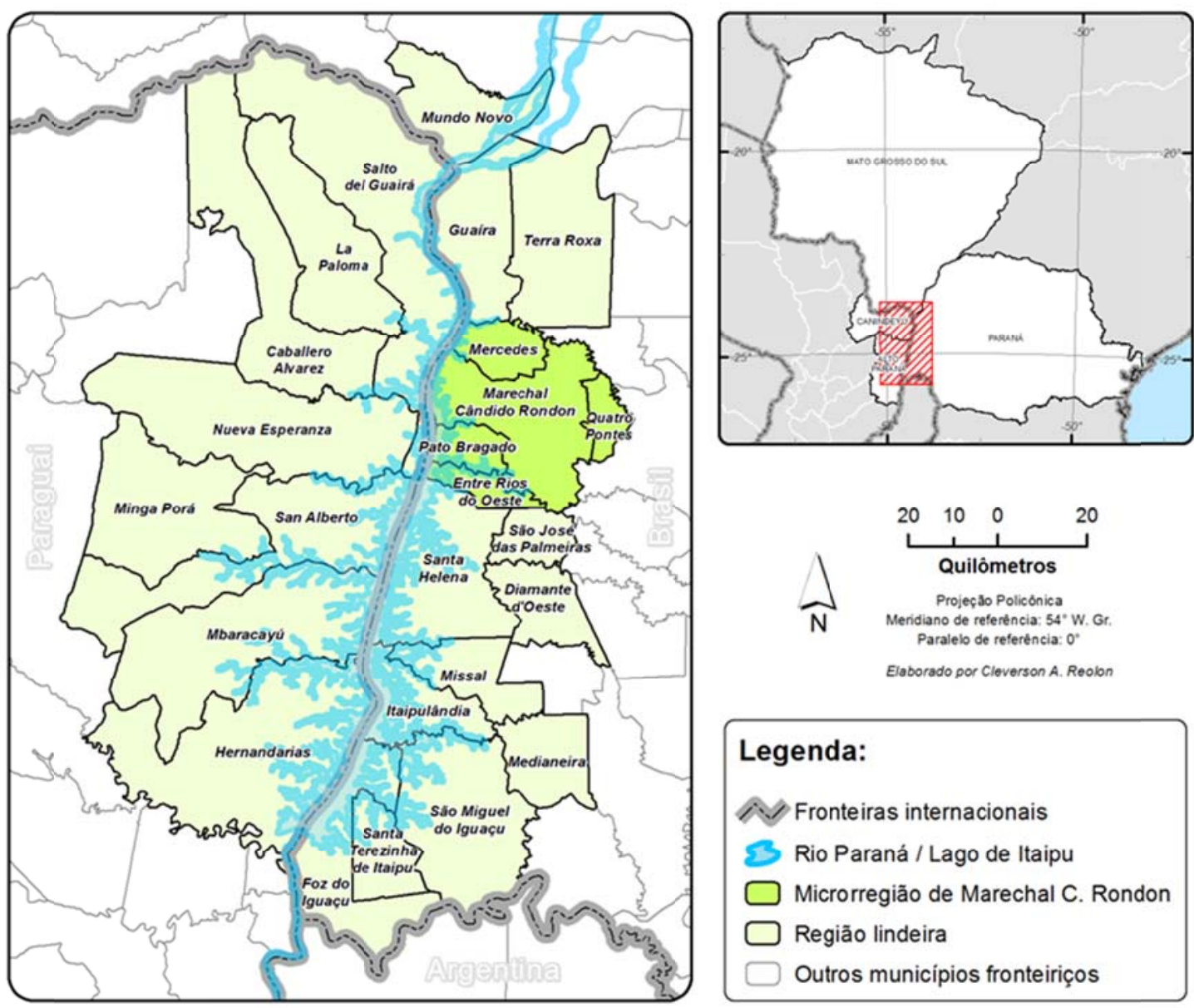

\section{Legenda:}

Fonte: Base Cartográfica do IBGE, 2005.

A história da Mesorregião Oeste Paranaense ou simplesmente Oeste do Paraná, que inclui os municípios da microrregião de MCR, está relacionada aos movimentos migratórios do Sul do Brasil, em especial do Rio Grande do Sul e de Santa Catarina, que iniciaram o processo de ocupação na década de 1940, por intermédio das empresas colonizadoras. Uma dessas empresas, a Maripá - Industrial Madeireira Colonizadora Rio Paraná -, além de explorar os recursos naturais, em destaque a madeira, tinha como finalidade colonizar a região Oeste do Paraná. Essa colonizadora passou a vender as terras, previamente divididas em pequenas propriedades, ocasionando uma significativa mudança na estrutura da região, onde as famílias migrantes passaram a ocupar as terras, antes utilizadas pelos mensus, trabalhadores paraguaios das obrages ${ }^{2}$, para extração da erva-mate e madeira.

Com a modernização da agricultura, ocorrida a partir de 1960, o Oeste do Paraná encerrou o período de ocupação e entrou numa nova fase econômica: a reestruturação da base produtiva. Essa reestruturação, que marcaria os anos de 1970 e 1980, foi estimulada

2 Obrages eram empreendimentos de exploração das propriedades do Oeste e Sudoeste do Paraná antes da colonização moderna da região. (GREGORY, 2002). 
pela modernização da base técnica da produção agropecuária, o aumento da produtividade da agropecuária regional, a ocupação intensiva do espaço regional e as grandes obras de infraestrutura (usinas hidroelétricas e estradas). O resultado foi o fortalecimento da economia e a urbanização acelerada pelo êxodo rural. (PIFFER, 1999).

Apesar da relevância histórica para se compreender o processo de ocupação e consequente início da formação do território, esta microrregião se constituiu pelo desmembramento do município de MCR. Os municípios de ERO, PB, QP e M tiveram como data de instalação o dia de 1\%1/1993, emancipados de MCR, este com data de instalação havida em 2/12/1961.

Todos os municípios que margeiam o lago de Itaipu, sendo 16 brasileiros ao todo (incluídos os da microrregião de MCR), estão, portanto, relacionados fisicamente pela formação do Lago de Itaipu, em 1982, após a construção da Usina Hidrelétrica de Itaipu, resultado de um acordo binacional entre Brasil e Paraguai que represou o Rio Paraná na linha de fronteira entre os dois países.

A construção da Hidrelétrica de Itaipu, uma das maiores do mundo, começou em 1974, período em que o Brasil vivia um padrão de ocupação territorial no qual o Estado e os grandes projetos de investimentos tiveram grande visibilidade. A década de 1970 foi caracterizada por investimentos de grande porte, aplicados na extração de recursos naturais e em infraestrutura energética, de transporte e de comunicação. Para Piquet (1998), o Brasil destacou-se como um dos países do Terceiro Mundo que individualmente mais aplicou nesse tipo de empreendimento, investimentos por intermédio dos quais foi promovida uma autêntica mutação da economia nacional. A produção do espaço, como resultado da intervenção direta do Estado, como sucedido em relação à inundação de áreas para geração de energia elétrica, concretizou a produção espacial e promoveu atividades econômicas diversas das predominantes anteriormente às transformações promovidas pelo Estado. (SOUZA, 2002; 2009a).

Teoricamente estão sendo interpretados alguns estudos que elucidem a relação da indústria com o espaço. Desta forma, tem sido possível analisar a relação existente entre os municípios localizados na microrregião de MCR e também a dimensão espacial existente entre a indústria e sua relação com o espaço e ou com o território. Lefebvre (2001) e Carlos (1991) são boas referências, além de Fischer, que também analisou as relações entre indústria e espaço na França. Perroux (1961 e 1975), com sua teoria de polo de desenvolvimento, nos auxilia a compreender a indústria como meio de se polarizar o crescimento de uma região. A centralidade exercida pela polarização de MCR é outro caminho investigativo. A regionalização sugerida por Limonad (2004) também tem demonstrado interesse por considerar a realidade regional existente. Santos (1996) demonstra a importância de se entender um lugar a partir de uma relação reticular (verticalidade) e da proximidade (horizontalidade).

Além dessa base teórico-metodológica, também se tem como base dados fornecidos pelo Instituto Brasileiro de Geografia e Estatística (IBGE), pelo Instituto Paranaense de Desenvolvimento Econômico e Social (IPARDES) e pela Dirección General de Estadísticas, Encuestas y Censos (DGEEC). 
A fim de pesquisar o número de empregos distribuídos por ramos de atividade, considerando que a ocupação da mão de obra é um elemento importante, utilizou-se da base de dados do Relatório Anual de Informação Social (RAIS) do Ministério do Trabalho e Emprego e do portal Indústrias do Extremo Oeste do Paraná (INDEXOPAR). Tais fontes contribuíram para informações socioeconômicas de cada município.

O artigo está organizado no seguinte sentido: além desta breve introdução, aborda-se uma síntese teórica do papel da indústria na produção do espaço, em seguida, a caracterização de MCR como polo industrial, depois a microrregião de MCR relacionada com a fronteira do Paraguai e Argentina e, por último, as considerações finais, sinalizando alguns resultados.

\section{O PAPEL DA INDÚSTRIA NA PRODUÇÃO DE ESPAÇO - REVISÃO TEÓRICA}

Segundo Lefebvre (2001, p. 123), “[...] o processo de industrialização, há um século e meio, é o motor das transformações na sociedade". Ainda que na esfera da produção a indústria na atualidade tenha deixado ser a mais importante, mas juntamente com todo o circuito da produção (a distribuição, a circulação/comercialização e o consumo), tem-se observado seu papel de interventor do espaço.

No circuito da produção, o desenvolvimento industrial pressupõe a concentração espacial beneficiando-se daquilo que os economistas chamam de "economias de aglomeração", mão de obra, proximidade de outras indústrias complementares, mercado diversificado e economia dos gastos de produção (CARLOS, 1991).

A relação entre a indústria e o espaço e ou o território é intrínseca, pois a localização e a dinâmica industrial necessitam de base física para a realização de sua produção, seja interna ou externa à cidade, pois

[...] a atividade industrial assume o papel de comando na reprodução espacial. Ela articula e subordina outras parcelas do espaço, pois o mercado de matérias-primas e auxiliares, e o mercado de destino dos produtos, necessariamente ultrapassam o nível espacial do lugar. (CARLOS, 1991, p. 38-39).

O espaço e o território são produzidos para atender, de um lado, às necessidades da produção e da circulação de mercado visando o funcionamento perfeito do ciclo do capital e, de outro, à reprodução humana. Conforme Saquet (2007), o espaço e o território são ligados e indissociáveis. Nesse contexto, o território é produzido espaço-temporalmente pelas relações de poder exercidas por determinados grupos ou classes sociais.

O tratamento de temas ligados ao fator industrial e sua relação com o espaço geográfico é uma das contribuições mais importantes da obra do professor André Fischer. Firkowiski e Sposito (2008), em uma revisão dos textos de André Fischer, deixam clara a necessidade de compreender a transformação do setor industrial, retratando a transição do modelo fordista para o flexível, caracterizado por outras relações, pelo forte papel da tecnologia e pela importância cada vez mais valorizada das Pequenas e Médias Empresas 
(PME) e Pequenas e Médias Empresas Industriais (PMI), em um contexto em que o valor do desenvolvimento endógeno - motor para o desenvolvimento local - é ressaltado e as coletividades devem criar estratégias para a atração das atividades econômicas.

Santos (1988) e Limonad (2004) destacam a relevância em analisar o espaço em uma perspectiva regional, alertando que sua composição deve ser detalhada visando à organização social, política, econômica e cultural, em fases diferentes de tempo e espaço. Ou seja, não podemos estudar a organização do espaço social sem esclarecer os fatos que lhes antecedem e sucedem.

Peris (2003), em sua análise, conceitua a divisão regional a partir da teoria de Friedmann, que define as regiões em dois tipos de critérios: homogeneidade e interação. $\mathrm{O}$ primeiro concerne à homogeneidade, que ocorre quando a região é definida de acordo com uma de suas características, podendo ser física, econômica ou outra. O segundo critério que o autor destaca é a região definida a partir da interação, que se manifesta na base da ação recíproca das atividades sociais e econômicas, que se orientam de maneira mais intensa rumo a um determinado centro.

Ou seja, a delimitação da microrregião de MCR pode ser definida a partir dessa análise conceitual, em região de interação, pois há um movimento populacional dos municípios vizinhos para o município de MCR, que, com a oferta de serviços mais complexos, apresenta-se como polo regional perante os outros municípios que a pesquisa abrange.

Assim, portanto, a formação de uma região se desdobra na construção social do espaço de uma sociedade: “Uma regionalização pode fundamentar uma reflexão teórica ou atender às necessidades impostas por uma política setorial, uma prática de planejamento ou por propostas de desenvolvimento regional" (LIMONAD, 2004, p. 58).

O conceito de polo de desenvolvimento ajuda na descrição e explicação das dinâmicas do crescimento econômico, principalmente para as economias capitalistas modernas. François Perroux foi o teórico que desenvolveu a teoria dos polos regionais. Para Perroux, devemos partir de observações e assim extrair os dados que irão designar as especificidades dos polos de crescimento. A observação é essencial, pois revela os dados que indicam o crescimento das modernas economias capitalistas e, muitas vezes, não se apresentam de maneira homogênea no interior de um espaço econômico, mas iniciam-se e propagam-se a partir de certos pontos com intensidades variáveis de irradiação, que se distribuem por canais diversos, resultando efeitos distintos para a economia em seu conjunto (PERROUX, 1961).

O crescimento é um processo polarizador em sua essência, pois na maneira como suas forças o induzem, operam no modo de coligar atividades em torno de contínuos centros de inovação resultando em desequilíbrios entre os setores industriais e por sua abrangência e extensão entre as regiões em que estão localizados. A indústria atua como principal meio de se polarizar o crescimento de uma região, considerando que "[...] o aparecimento de uma ou várias indústrias altera, diz-se correntemente, a 'atmosfera' de uma época, cria um 'clima' favorável ao crescimento e ao progresso" (PERROUX, 1975, p. 104).

Ao tratar de desenvolvimento regional, Moura (2009) aponta que a presença de população é um fator fundamental na oferta de funções urbanas qualificadas. Dessa forma, os municípios menores tornam-se dependentes daqueles que apresentam maior 
centralidade. A autora deixa claro, porém, que os municípios polarizadores de serviços não tornam os menores subordinados, senão que racionalizam as funções de maior complexidade. Um fator preponderante no desenvolvimento das microrregiões é o neolocalismo competitivo, quando os municípios de uma microrregião passam a incitar a guerra dos lugares, "[...] reduzindo o território municipal a uma plataforma vantajosa a investidores" (MOURA, 2004, p. 33). A centralidade é outro aspecto da concentração de produtos, serviços e de troca, considerando os atrativos existentes, bem como a economia de aglomeração que dará suporte a essa centralidade. Nesse sentido, segundo Tourinho (2005, p. 290), “[...] a centralidade, como qualidade do que é central, tornou-se ela própria medida, passando a identificar a aptidão que certos elementos urbanos têm para promover e impulsionar fluxos de intercâmbio".

Dumas, Malo e Raefflet (2005 apud FERRERA DE LIMA, 2007) assinalam que a dinâmica econômica, e com ela o desenvolvimento, estrutura-se em torno de dois elementos essenciais: as empresas com suas potencialidades e limites e o Estado, com suas estratégias de intervenção, planejamento e desenvolvimento. No caso das empresas, os estudos do seu perfil aglomerativo, da sua capacidade de interação no conjunto do ramo de atividade e sua capacidade competitiva são elementos essenciais de inserção no mercado globalizado e sua expansão a longo prazo. No caso da intervenção estatal, o conhecimento dos elementos mencionados é a diretiva básica para o planejamento do desenvolvimento econômico regional.

Para Furtado (1987), um dos elementos-chave do desenvolvimento é a melhora no perfil produtivo do trabalhador. Por outro lado, uma melhor localização em relação aos mercados ou fontes de matéria-prima também oferece a possibilidade de se auferir uma maior produtividade. Em alguns caos, a cooperação e/ou a proximidade de determinados ramos produtivos também são estratégicos para se obter ganhos de escala na estrutura produtiva.

Além da localização, Santos (1996) nos ensina que os lugares se expressam pelas horizontalidades e verticalidades. As relações de horizontalidades podem ser lidas nos serviços que a cidade presta em seu entorno e que exigem deslocamentos periódicos da população: saúde, educação, comércio especializado, serviços públicos e bancários, dentre outros. Já as verticalidades inserem os espaços em graus e formas variadas num contexto global, os quais se utilizam dos benefícios da informação, haja vista a capacidade de unir em redes os diferentes espaços.

\section{MARECHAL CÂNDIDO RONDON, UM POLO INDUSTRIAL}

Apesar da colonização da região iniciar no século XX, antes mesmo da chegada dos colonizadores, vindos principalmente do Rio Grande do Sul e de Santa Catarina, essa parte do Paraná havia despertado o interesse de empresários pela madeira existente em abundância. Impulsionadas por política do governo federal em ocupar as fronteiras do país, mediante a chamada Marcha para o Oeste, companhias madeireiras instalaram-se na região, dando início a uma intensa indústria extrativista, que acabou por dar condições para que fosse iniciada a colonização. 
O município de MCR ganhou força política e econômica com o processo de colonização, exercendo certa polarização em relação a alguns municípios vizinhos. Reflexos deste período histórico se traduzem na primazia populacional em relação aos municípios da microrregião em análise, conforme Tabela 1.

Tabela 1 - Dados Populacionais e Área dos municípios da Microrregião de Marechal Cândido Rondon-PR -2010

\begin{tabular}{|c|c|c|c|c|c|c|}
\hline \multirow{2}{*}{ MUNICÍPIO } & \multicolumn{3}{|c|}{ POPULAÇÃO } & \multirow{2}{*}{$\begin{array}{c}\text { GRAU DE } \\
\text { URBANIZAÇÃO } \\
(\%)\end{array}$} & \multirow{2}{*}{$\begin{array}{c}\text { DENSIDADE } \\
\text { DEMOGRÁFICA } \\
(\%)\end{array}$} & \multirow{2}{*}{$\begin{array}{c}\text { ÁREA } \\
\left(\mathbf{k m}^{2}\right) / 1000\end{array}$} \\
\hline & Total & Urbana & Rural & & & \\
\hline Entre Rios do Oeste & 3.992 & 2.641 & 1.281 & 67.34 & 35.59 & 120,33 \\
\hline $\begin{array}{c}\text { Marechal Cândido } \\
\text { Rondon }\end{array}$ & 46.799 & 39.134 & 7.665 & 83.62 & 62.54 & 748,33 \\
\hline Mercedes & 5.046 & 2.439 & 2.607 & 48.34 & 25.35 & 199,08 \\
\hline Pato Bragado & 4.823 & 2.991 & 1.832 & 62.02 & 35.26 & 136,78 \\
\hline Quatro Pontes & 3.804 & 2.436 & 1.368 & 64.04 & 33.21 & 114,53 \\
\hline
\end{tabular}

Fonte: IBGE - Censo Demográfico 2010. Ipardes, 2010. Org.: autor

Tabela 2 - Valor Adicionado Bruto (VAB) dos municípios da microrregião de $\operatorname{MCR}(\operatorname{R} \$ 1.000,00)$

\begin{tabular}{c|c|c|c|c}
\hline MUNICÍPIO & $\begin{array}{c}\text { VAB } \\
\text { Total }\end{array}$ & $\begin{array}{c}\text { VAB } \\
\text { Agropecuário }\end{array}$ & $\begin{array}{c}\text { VAB } \\
\text { Indústria }\end{array}$ & $\begin{array}{c}\text { VAB } \\
\text { Serviços }\end{array}$ \\
\hline Entre Rios do Oeste & 63,94 & 22,27 & 4,11 & 37,56 \\
\hline Marechal Cândido Rondon & 813,95 & 122,62 & 206,65 & 484,69 \\
\hline Mercedes & 78,84 & 33,9 & 7,64 & 37,3 \\
\hline Pato Bragado & 53,99 & 18,17 & 6,05 & 29,77 \\
\hline Quatro Pontes & 70,83 & 31,67 & 11,24 & 27,93 \\
\hline
\end{tabular}

Fonte: IBGE/Ipardes - 2008. Disponível em: <www.ipardes.gov.br/perfil_municipal/MontaPerfil.php?Municipio $=85960 \&$ btOK $=$ ok $>$. Acesso em: 3 ago. 2011. Org.: autor

A microrregião de MCR não está institucionalizada como tal, mas possui uma dinâmica própria, dada pela constante interação entre os municípios que a integram (ERO, M, PB e QP), verificada tanto no âmbito da mobilidade populacional, quanto entre os setores produtivo e de comércio, serviço, comunicação e informação. A Tabela 2 apresenta o Valor Adicionado Bruto (VAB) a Preços Básicos dos principais setores produtivos da microrregião de MCR.

Já a Tabela 3 demonstra o Valor Adicionado Fiscal (VAF) dos municípios da microrregião de MCR. Ainda que o VAB da indústria de MCR não seja superior ao VAB de serviços, o setor produtivo industrial é relevante, como é também superior ao VAB da indústria na somatória dos municípios contíguos.

Constata-se que tanto o VAB como o VAF do município de MCR é maior que os VAB e VAF dos demais municípios. Reflexo do VAB e do VAF, o ICMS por município de origem do contribuinte destaca MCR dos demais. Assim, temos em 2010, segundo dados da Secretaria Estadual da Fazenda (SEFA), em ordem decrescente de arrecadação: MCR: R\$ 8.586.483,83; QP: R\$ 986.720,06; M: R\$ 313.735,83; ERO: R\$ 227.278,23 e PB: R\$ $131.671,37$. 
Segundo a interpretação dos VAFs da Tabela 3, o setor econômico que possui grande importância e contribui para a compreensão espacial dessa microrregião é a indústria, pois influencia os fluxos regionais atraindo mão de obra e gerando renda aos municípios, ainda que o VAF da produção primária seja maior. A Tabela 4 ilustra parcialmente essa mobilidade. Por meio dessa tabela, pode-se observar que todos os municípios da microrregião possuem trabalhadores no Frigorífico de Aves Copagril, destacando-se que o maior número é proveniente de MCR.

Tabela 3 - Valor Adicionado Fiscal dos municípios da microrregião de MCR

\begin{tabular}{c|c|c|c|c|c}
\hline \multirow{2}{*}{ MUNICÍPIO } & $\begin{array}{c}\text { VAF } \\
\text { Total }\end{array}$ & $\begin{array}{c}\text { VAF } \\
\text { Produção Primária }\end{array}$ & $\begin{array}{c}\text { VAF } \\
\text { Indústria }\end{array}$ & $\begin{array}{c}\text { VAF } \\
\text { Comércio/Serviços }\end{array}$ & $\begin{array}{c}\text { VAF } \\
\text { Recursos/Autos }\end{array}$ \\
\hline ERO & $88.696 .584,00$ & $70.967 .939,00$ & $5.151 .434,00$ & $12.572 .153,00$ & 5,06 \\
\hline MCR & $699.776 .142,00$ & $269.115 .081,00$ & $236.727 .895,00$ & $190.678 .867,00$ & $3.254 .299,00$ \\
\hline M & $78.500 .087,00$ & $60.273 .222,00$ & $10.649 .247,00$ & $7.561 .181,00$ & $16.437,00$ \\
\hline PB & $78.489 .544,00$ & $59.955 .453,00$ & $8.758 .654,00$ & $8.593 .845,00$ & $1.181 .592,00$ \\
\hline QP & $110.829 .488,00$ & $79.198 .381,00$ & $22.939 .691,00$ & $8.682 .063,00$ & 9.35 \\
\hline
\end{tabular}

Fonte: Secretaria Estadual da Fazenda (SEFA) - 2009. Disponível em: <www.ipardes.gov.br/perfil_municipal/MontaPerfil,php ?Municipio=85960\&btOK=ok.>. Acesso em: 3 ago. 2011. Org.: autor

Tabela 4 - Trabalhadores que se deslocam diariamente para o trabalho no Frigorífico de Aves da Copagril - (2008-2010)

\begin{tabular}{|c|c|c|c|}
\hline Município & $\begin{array}{l}N^{0} \text { de trabalhadores e \% } \\
\text { em relação ao total - } 2008\end{array}$ & $\begin{array}{l}N^{0} \text { de trabalhadores e \% } \\
\text { em relação ao total - } 2009\end{array}$ & $\begin{array}{l}N^{0} \text { de trabalhadores e } \% \\
\text { em relação ao total - } 2010\end{array}$ \\
\hline $\begin{array}{c}\text { Marechal Cândido } \\
\text { Rondon }\end{array}$ & $976-62,5$ & $716-44,5$ & $666-43$ \\
\hline $\begin{array}{c}\text { São José das } \\
\text { Palmeiras }\end{array}$ & $178-11,5$ & $206-13$ & $131-8,5$ \\
\hline Santa Helena & $144-9,3$ & $150-9,3$ & $131-8,5$ \\
\hline $\begin{array}{l}\text { São Pedro do } \\
\text { Iguaçu }\end{array}$ & $50-3,3$ & $37-2,3$ & $37-2,5$ \\
\hline Guaíra & $49-3,2$ & $142-9,0$ & $115-7,5$ \\
\hline $\begin{array}{c}\text { Ouro Verde do } \\
\text { Oeste }\end{array}$ & $35-2,2$ & $82-5,2$ & $75-5,0$ \\
\hline Entre Rios do Oeste & $29-1,8$ & $19-1,1$ & $16-1,0$ \\
\hline Pato Bragado & $22-1,4$ & $16-1,0$ & $14-1,0$ \\
\hline Toledo & $20-1,2$ & $12-0,7$ & $17-1,1$ \\
\hline Mercedes & $20-1,2$ & $15-0,9$ & $14-1,0$ \\
\hline Quatro Pontes & $11-0,7$ & $08-0,4$ & $07-0,5$ \\
\hline Diamante do Oeste & - & $84-5,3$ & $65-4,2$ \\
\hline Missal & - & - & $17-1,1$ \\
\hline Nova Santa Rosa & - & - & $29-1,9$ \\
\hline Mundo Novo - MS & $26-1,7$ & $73-4,5$ & $66-4,2$ \\
\hline Japorã -MS & - & $06-0,3$ & $13-1,0$ \\
\hline Eldorado-MS & - & $40-2,5$ & $126-8,0$ \\
\hline Total & $1560-100$ & $1606-100$ & $1539-100$ \\
\hline
\end{tabular}


Ao designar uma cidade como central, devemos verificar primordialmente as relações entre centro e centralidade. Para Tourinho (2005), a cidade central caracteriza-se por ser um espaço qualificado, não apenas de maneira funcional, mas também por aspectos simbólicos e formais, fazendo com que a centralidade seja construída ao longo do tempo em determinados espaços que estreitam as relações interpessoais, revelando significados com base na história dos municípios.

A atração populacional ao centro se consolida com a maior oferta de trabalho e maior prestação de serviços de estabelecimentos públicos e privados. De acordo com os dados da Tabela 5, podemos analisar que o município de MCR possui mais atividades industriais em relação aos municípios vizinhos. Isso motiva a atração de trabalhadores desses municípios, que buscam melhores salários e desenvolvimento profissional.

Tabela 5 - Estabelecimentos segundo as atividades econômicas na Microrregião de Marechal Cândido Rondon (PR) - 2009

\begin{tabular}{|c|c|c|c|c|c|}
\hline MUNICÍPIOS & MCR & $\begin{array}{c}\text { Entre Rios } \\
\text { do Oeste }\end{array}$ & $\begin{array}{c}\text { Pato } \\
\text { Bragado }\end{array}$ & Mercedes & $\begin{array}{l}\text { Quatro } \\
\text { Pontes }\end{array}$ \\
\hline Indústria de extração de minerais & 1 & 0 & 0 & 0 & 0 \\
\hline Indústria de produtos minerais não metálicos & 12 & 3 & 3 & 2 & 3 \\
\hline Indústria metalúrgica & 33 & 2 & 3 & 3 & 3 \\
\hline Indústria mecânica & 20 & 1 & 2 & 1 & 3 \\
\hline Indústria de materiais elétricos e de comunicação & 2 & 1 & 1 & 1 & 3 \\
\hline Indústria de materiais de transporte & 11 & 1 & 0 & 1 & 0 \\
\hline Indústria da madeira e do mobiliário & 17 & 4 & 4 & 3 & 8 \\
\hline Indústria do papel, papelão, editorial e gráfica & 18 & 0 & 0 & 0 & \\
\hline Indústria da borracha, fumo, couros, peles & 9 & 0 & 0 & 0 & 0 \\
\hline Indústria química & 5 & 1 & 0 & 0 & 1 \\
\hline $\begin{array}{l}\text { Indústria têxtil, do vestuário e artefatos de teci- } \\
\text { dos }\end{array}$ & 18 & 2 & 9 & 2 & 3 \\
\hline Indústria de calçados & 2 & 0 & 1 & 0 & 0 \\
\hline Indústria de produtos alimentícios. & 46 & 6 & 8 & 8 & 7 \\
\hline Serviços industriais de utilidade pública & 3 & 0 & 1 & 1 & 1 \\
\hline Construção civil & 110 & 7 & 9 & 3 & 4 \\
\hline Comércio varejista & 678 & 49 & 81 & 42 & 32 \\
\hline Comércio atacadista & 55 & 4 & 7 & 3 & 1 \\
\hline Instituições de crédito e seguro & 19 & 2 & 1 & 2 & 2 \\
\hline Administradoras de imóveis & 108 & 4 & 7 & 3 & 5 \\
\hline Transporte e comunicações & 123 & 8 & 10 & 6 & 22 \\
\hline Serviços de alojamento, radiodifusão e televisão & 153 & 14 & 27 & 16 & 11 \\
\hline Serviços médicos, odontológicos e veterinários & 66 & 4 & 6 & 3 & 3 \\
\hline Ensino & 22 & 1 & 2 & 1 & 1 \\
\hline Administração pública direta e indireta & 3 & 2 & 2 & 2 & 3 \\
\hline $\begin{array}{l}\text { Agricultura, silvicultura, criação de animais, } \\
\text { extração vegetal e pesca }\end{array}$ & 151 & 42 & 17 & 14 & 21 \\
\hline TOTAL & 1.685 & 159 & 201 & 116 & 137 \\
\hline
\end{tabular}




\section{Estudo de Reolon (2007, p. 6) já demonstra que}

[...] os fluxos de pessoas entre os diversos distritos situados no Oeste Paranaense estão se ampliando rapidamente à medida que as empresas de transporte coletivo têm implantado novas linhas, a partir de 2000, permitindo, aos habitantes das pequenas localidades, maior acesso aos bens, serviços públicos e privados e empregos ofertados [...].

Dados do Relatório Anual de Informação Social (RAIS) do Ministério do Trabalho e Emprego demonstram que o emprego industrial do Oeste do Paraná tem apresentado um crescimento contínuo desde 2002, com taxas próximas a 10 pontos percentuais ao ano. As indústrias alimentícias e as agroindústrias são as que mais empregam na região. Segundo dados do Ipardes (apud HECK; CARVALHAL, 2010), em relação ao número de empregos no mercado de trabalho formal no município, a participação das indústrias alimentícias saltou 35 pontos percentuais em onze anos, ou seja, de 34 pontos percentuais, contabilizados em 1998, ampliou-se para 69 pontos percentuais em 2009. Em números absolutos, significa um salto de 365 para 3.308 empregos entre os anos de 1998 e 2009.

Levantamento preliminar de algumas pesquisas (GEMELLI, 2009; CARVALHAL, 2008; CÊA, 2008; HECK; CARVALHAL, 2010) demonstra a precarização do trabalho nas indústrias da região, expondo as condições de muitos trabalhadores em extenuantes jornadas de trabalho. Estudar isso não é o foco deste projeto, no entanto, não poderão ser omitidas informações sobre essa realidade da indústria da microrregião.

Em paralelo a essa realidade, outro índice que motiva a atração populacional é determinado pelos estabelecimentos de consulta à saúde ${ }^{3}$, tanto públicos como privados, sendo esse um elemento de relevância por interferir diretamente na qualidade de vida dos moradores da região, que buscam em MCR serviços especializados nessa categoria. Dados da Tabela 5 demonstram parcialmente essa realidade. E, assim, a centralidade é evidenciada com a produção e a circulação de bens, resultando em mais recolhimento de impostos e, concomitantemente, em mais investimentos públicos e em concentração de serviços.

Segundo o Censo de 2010 do IBGE, três municípios da microrregião de MCR estão entre os dez municípios com renda per capita acima da média estadual, que é de $\mathrm{R} \$$ 876, 00, sendo: Entre Rios do Oeste (R\$ 1.021,59), Quatro Pontes (R\$ 909,76) e Marechal Cândido Rondon (R\$893,18). A Tabela 6 sintetiza os principais dados socioeconômicos e financeiros dessa microrregião, como segue.

3 A melhoria do atendimento à saúde poderá ser um novo indicador de qualidade de vida na fronteira, se considerarmos a efetivação da Portaria no 1188/GM, de 5 de junho de 2006, que institui o Sistema Integrado pela Saúde das Fronteiras. Propõe: "a formalização de integração entre sistemas de saúde de fronteiras, a partir do reconhecimento das dificuldades historicamente vivenciadas por gestores e usuários nestas localidades...". A portaria ainda identifica a necessidade de consolidar e expandir a atuação do Ministério da Saúde no âmbito das fronteiras, ou seja, a consolidação do SUS nos estados brasileiros (RS, SC, PR, MS, MT, AC, RO, PA, AM, RR e AP) e a possibilidade de cooperação entre países vizinhos para melhoria da gestão. A consolidação do SUS nos estados e municípios brasileiros, com foco na organização de serviços e a criação de um sistema de cooperação em rede entre os municípios com fronteiras internacionais são ações que buscam a melhoria da qualidade de vida da população dos municípios. Dentro dessa perspectiva, alguns municípios já estão elaborando um diagnóstico local para receber os recursos destinados do Ministério da Saúde, dentre eles, Mercedes, da microrregião de MCR. 
Tabela 6 - Indústrias e royalties na Microrregião de MCR

\begin{tabular}{c|c|c|c}
\hline MUNICÍPIO & $\begin{array}{c}\mathbf{N}^{\mathbf{0}} \text {. de indústrias } \\
\mathbf{( 0 5 / 2 0 1 1 )}\end{array}$ & $\begin{array}{c}\mathbf{N}^{\mathbf{0}} \text {. de empregos } \\
\mathbf{( 0 5 / 2 0 1 1 )}\end{array}$ & Royalties (05/2011) \\
\hline $\begin{array}{c}\text { Entre Rios do Oeste } \\
\begin{array}{c}\text { Marechal Cândido } \\
\text { Rondon }\end{array}\end{array}$ & 21 & 158 & US\$ 115,3 mil \\
\hline Mercedes & 20 & 4557 & US\$ 196,4 mil \\
\hline Pato Bragado & 27 & 220 & US\$ 67,7 mil \\
\hline Quatro Pontes & 29 & 343 & US\$ 164,9 mil \\
\hline Total & 286 & 5494 & 0 \\
\hline
\end{tabular}

Fonte: INDEXOPAR e Itaipu Binacional. Org.: SCHAEFER, Djessyca A.

Aspecto de grande relevância regional e que potencializa economicamente cada município é o recebimento dos royalties, com exceção de QP. Conforme demonstra a mesma Tabela 6, MCR recebe mensalmente a maior quantidade em relação ao conjunto da microrregião. Os royalties representam uma receita a mais a esses municípios, especialmente àqueles que estão nas margens do Lago de Itaipu. São valores significativos para promover o desenvolvimento com base em uma política de planejamento. Segundo o Tratado de Itaipu, assinado em 1973 entre Brasil e Paraguai, o recebimento dos royalties termina em 2023.

Paralelamente ao recebimento dos royalties, a indústria e o inerente processo de industrialização possuem grande potencialidade de fortalecimento dos desenvolvimentos local e microrregional. É importante, no entanto, que os gestores públicos e a sociedade civil promovam o planejamento do investimento desse recurso, garantindo a sustentabilidade e o processo de desenvolvimento: “Deve-se repensar a aplicação dos royalties em programas e projetos que garantam o desenvolvimento local e regional aliado à qualidade de vida de seus munícipes, atentando para a possibilidade de que o repasse do recurso possa ser encerrado" (STERCHILE; SOUZA, 2008, p. 19).

Em entrevista à imprensa regional, o prefeito de MCR, Moacir Froehlich (gestão 2009-2012), enaltece o município dizendo que "[...] tem alcançado um desenvolvimento formidável nos últimos anos, principalmente no setor industrial" (DESTAQUE, 2011). Segundo ele, pesquisas apontam que a indústria está no topo, na geração de emprego e renda, seguida do setor da prestação de serviços e, em terceiro lugar, do setor agropecuário. Apesar das controvérsias, como a precarização do trabalho já apontada anteriormente, problemática analisada por alguns autores citados.

As indústrias são capazes de inserir os lugares na mundialização dos mercados, pois "A globalização configura lugares, tornando-os cada vez mais heterogêneos, dotados de uma diferenciação espacial caracterizada pelo surgimento de múltiplos territórios" 
(HAESBAERT; PORTO GONÇALVES, 2006, p. 127). Essas mesmas indústrias, ao mesmo tempo em que se distinguem pelas suas diferenças identitárias, também se conectam e se sobrepõem pelo emaranhado complexo das redes que constituem o espaço geográfico atual.

Algumas indústrias ${ }^{4}$ de MCR se destacam: a Sooro, indústria líder do mercado de processamento de soro de leite no Brasil, e a Frimesa, indústria de lacticínios. Ambas as empresas requerem matéria-prima que se encontra em abundância na região, como o leite, cereais (soja e milho), suínos e aves. Também se destaca a indústria Schumacher, que atua nas áreas pneumáticas e hidráulicas, servindo o território nacional e exportando para vários países. A empresa Sorasa Truck Center tem alcançado destaque regional no ramo de peças para caminhões e veículos. Também integra esse rol a Cooperativa Agroindustrial (Copagril), indústria de aves com capacidade de abate de 150 mil aves/ dia, gerando cerca de 1.700 empregos diretos, resultando a maior arrecadação de tributos municipais da área de atuação da cooperativa, além de exportar para todos os continentes:

A participação da Copagril nestas quatro décadas na região é feita não somente pela arrecadação tributária que a ela corresponde, mas sim, por empregos, renda, capacitação profissional dos funcionários, investimentos em jovens cooperados, núcleos de mulheres associadas e seus projetos em educação e cultura, a efetiva participação no esporte, descobrindo talentos e com isso destacando a cidade e a região em âmbito nacional. (QUATRO, 2011, p. 17).

Outras indústrias de relevância nacional e regional podem ser mencionadas, como a Tecsoft - indústria de máquinas de sorvete, a Tropical Cabines - indústria de cabines para camionetes, a Faville - indústria de biscoitos e macarrão, e a Agrícola Horizonte, que gera mais de 3 mil empregos no setor de alimentos.

No município de MCR, estão sendo ampliadas as áreas destinadas às indústrias, com investimentos na construção de uma nova incubadora no Parque Industrial II e que atenderá a oito novas empresas. Já no Parque Industrial III, está prevista a pavimentação com pedras irregulares, meio-fio e galerias de águas.

Outras ações também estão sendo implementadas, como é o caso do anel de integração e desenvolvimento, que prevê a implantação de áreas industriais na região, obra prevista pelo plano diretor do município, o que fará com que as indústrias que estejam dentro do espaço urbano se mudem para locais específicos, onde possam desenvolver suas atividades, o que facilitará o escoamento da produção e também diminuirá o fluxo intenso de veículos de carga dentro do perímetro urbano.

4 Segundo o IBGE, os ramos das atividades produtivas são agrupadas de acordo com a seguinte classificação: 1) indústrias dinâmicas: indústria metalúrgica; indústria mecânica; indústria de material elétrico e das comunicações; indústria de material de transporte; indústria do papel, papelão, editorial e gráfica; indústria química de produtos farmacêuticos, veterinários e perfumaria; 2) indústrias tradicionais: indústria de madeira e mobiliário; indústria têxtil do vestuário e artefatos de tecidos; indústria de calçados; indústria de produtos alimentícios e bebidas; indústria extrativa mineral; 3) indústrias não tradicionais: indústria de produtos minerais não metálicos; indústria da borracha, fumo, couros e similares; indústria da construção civil; 4) terciário: comércio e serviços; 5) primário: agricultura e silvicultura. 


\section{A MICRORREGIÃO DE MCR E A FRONTEIRA COM O PARAGUAI E ARGENTINA}

Estudo do Ipardes (2008) sobre a Mesorregião Oeste Paranaense direcionou para leituras mais aprofundadas e detalhadas das espacialidades, definindo uma sequência de análises iniciada pelo recorte correspondente a essa região do Estado:

Última fronteira" de ocupação e expansão da exploração agropecuária, essa porção do Estado reúne indicadores econômicos e institucionais que a situam entre os três espaços de maior relevância do Estado, sendo uma das regiões onde a complementaridade das atividades produtivas resulta em uma agroindústria dinâmica com importantes impactos regionais, capazes de provocar rearranjos na estrutura fundiária local e na configuração populacional, consolidando uma densa rede de cidades. (IPARDES, 2008, p. 9).

Estudo realizado por Ferrera Lima (2003) mostra que o perfil competitivo da economia da região Oeste do Paraná, no âmbito do Mercosul, deve-se à forma como foi estruturado seu aparelho produtivo e, principalmente, ao perfil dos custos de produção e de transportes, para colocar suas mercadorias junto aos consumidores dos outros países: "O custo de produção de alguns produtos brasileiros chega a ser de $40 \%, 50 \%$ ou $60 \%$ a mais que o custo da produção de produtos na Argentina e do Paraguai" (SOUZA, 2009b, p. 112-113).

Na região Oeste do Paraná, esses custos estão mudando, considerando os investimentos industriais no setor de alimentos de carnes. De acordo com o Novo Mapa da Economia (TERRA, 2006), a Cooperativa Agroindustrial (Copagril) gastará, nos próximos anos, R\$ 160 milhões na ampliação de seu aviário, dobrando a capacidade de frigorífico em MCR.

Para Ferrera Lima (2003 apud SOUZA, 2009b, p.113),

[...] a região Oeste do Paraná está próxima a uma área sui generis no Cone Sul, que é a região mediterrânea do rio Paraná, que envolve o Nordeste argentino, o Sudeste paraguaio e o Oeste do Estado do Paraná. O que leva a pensar na possibilidade de uma integração intra-Mercosul, alavancada nos municípios da região, principalmente pelos interesses das municipalidades de Corrientes e de Posadas (Argentina), de Ciudad de Leste (Paraguai), de Cascavel e de Foz do Iguaçu (Brasil), cujo Fórum Permanente dos Municípios do Mercosul poderá ser um elemento aglutinador desses interesses.

O novo Programa de Desenvolvimento da Faixa de Fronteira (PDFF), do Ministério de Integração Nacional, depara-se com desafios estratégicos visando a mudança de mentalidade no tocante às fronteiras, que não podem mais ser entendidas como áreas longínquas e isoladas, mas sim, como uma região com a singularidade de estimular processos de desenvolvimento e integração regional (MACHADO, 2005). Para o governo brasileiro, gestão 2007-2010, o desenvolvimento da faixa de fronteira configura-se como importante diretriz da política nacional e internacional. Conforme o programa, 
[...] uma das estratégias principais de combate às desigualdades, fortalecimento e viabilidade dos potenciais endógenos e resgate da dívida social com uma população em história situação de vulnerabilidade, o desenvolvimento regional foi definido como prioritário nesse governo. A grande inovação desta política refere-se à abordagem dirigida a espaços sub-regionais, buscando a dinamização econômica e social e a melhoria das condições de cidadania, envolvendo o fortalecimento dos atores locais e o aproveitamento das peculiaridades da organização social e das características produtivas locais. (PROGRAMA, 2008 apud SOUZA, 2009a, p.114).

A localização da microrregião de MCR na zona de fronteira com o Paraguai configura-se como um espaço sub-regional, conforme o PDFF, pois:

[...] compreende-se que a distribuição da população e a análise das bases produtivas

é um instrumento valioso para entender o fenômeno urbano nas diferentes regiões e em diferentes esferas, capaz de traduzir informações importantes sobre a organização social, cultural e política, demonstrando aspectos peculiares de cada região e grau de envolvimento na expansão do sistema capitalista. (SOUZA, 2011, p. 20).

\section{CONSIDERAÇÕES FINAIS}

O presente estudo se desdobra em leituras e dados que possibilitaram a compreensão do papel da indústria na ocupação do espaço na microrregião de MCR, pois influencia sobremaneira os fluxos regionais, atraindo mão de obra e gerando renda aos municípios, assim como a interdependência dos municípios que perfazem a área estudada. Pela análise dos dados obtidos, comprova-se que MCR se constitui como um polo industrial microrregional, pois atende não só à demanda do município, mas também à de seus vizinhos.

A importância das indústrias de MCR tem influenciado o fluxo de bens e serviços, pois a relação do setor industrial com setores a montante, matéria-prima disponível, e a jusante, economia de aglomeração que proporciona suporte ao desenvolvimento industrial, dinamiza a economia da microrregião de MCR.

Cabe entender, porém, que todos os municípios da microrregião de MCR estão interligados, seja pelo fornecimento ou pela absorção de mão de obra, seja pelo fluxo de serviços ou ainda pela permeabilidade de ações e de informações. Apesar de não terem a centralidade de MCR, os outros municípios da microrregião participam do desenvolvimento regional com seus processos históricos, sociais e econômicos, constituindo-se em uma formação socioespacial.

Diante da análise dos dados, é necessário que os gestores públicos convirjam ações de um planejamento regional integrado para otimizar o setor produtivo em prol do desenvolvimento. As propostas de formulação de políticas públicas devem ser condizentes com as especificidades de cada grupo populacional e de sua incidência no território. 
O estudo ora realizado não prescinde de uma análise reticular, no entanto, a reflexão geográfica da especificidade horizontal foi o foco para elucidar o significado da escala local e microrregional para o desenvolvimento.

\section{REFERÊNCIAS}

AZEVEDO, S. T.; SOUZA, E. B. C. Mal. Cândido Rondon como polo de desenvolvimento microrregional. In: Seminário Internacional sobre espaços de fronteira. III Seminário Regional sobre Território, Fronteira e Cultura. VII Expedição Geográfica da Unioeste: espaços de fronteira - territórios e ambiente. Anais... Mal. Cândido Rondon (PR): Unioeste, 14 a 19 de set. de 2011.

Disponível em: http://www.unioeste.br/eventos/geofronteira

CARLOS, A. F.. Espaço e indústria. São Paulo: Contexto, 1991.

CARVALHAL, M. D. O trabalho e a dinâmica territorial do capital. Pegada, v. 9, n.1, p.123-135, out. 2008.

CÊA, G. S. dos S.. Associação dos Portadores de LER (AP_LER) na luta pelos direitos dos trabalhadores de frigoríficos do Oeste do Paraná. In: TUMOLO, P. S.; BATISTA, R. L. (Orgs.). Trabalho, economia e educação: perspectivas do capitalismo global. Maringá: Práxis/Massoni, v. 1, 2008. p. 421-436.

DESTAQUE estadual. Jornal O Presente, Mal. Cândido Rondon-PR, 7 de julho de 2011.

DUMAIS, S.; MALO, M.-C.; RAEFFLE, E. Les liens d'interrelation et lê dynamisme économiqur d'une MRC gaspésienne. Organizations et Territoires, Quebec, v. 14, n. 1, p.79-86, hiver 2005.

FERRERA LIMA, J. Integração da região: Paraná, Brasil e Paraguai. In: PERIS, A. F. (Org.). Estratégias de desenvolvimento regional. Cascavel, PR: Edunioeste, 2003. p. 179-192.

FERRERA LIMA, J. Dispersão espacial e alocação de emprego nas atividades produtivas nas microrregiões paranaenses. Toledo, PR: [s.n.], 2007. (Texto para Discussão). 21 p.

FIRKOWISKI, O. L. C.; SPOSITO, E. S. (Orgs.). Indústria, ordenamento do território e transportes: a contribuição de André Fischer. São Paulo: Expressão Popular, 2008. 160 p.

FURTADO, C. Teoria e política de desenvolvimento econômico. 19. ed. São Paulo: Cia. Editora Nacional, 1987.

GEMELLI, D. D. Capital, território e trabalho no Oeste paranaense: o frigorífico de aves da Copagril. Pegada, v. 10, n. 2, p.1-13, dez. 2009.

Mobilidade territorial do trabalho como expressão da formação para o trabalho: Frigorífico de Aves da Copagril de Marechal Cândido Rondon/PR. Dissertação (Mestrado). Francisco Beltrão, PR: Unioeste, 2011.

GEMELLI, V. Regionalização: a contradição de dois territórios na fronteira Brasil/Paraguai. In: ENCONTRO NACIONAL DA ASSOCIAÇÃO NACIONAL DE PÓS-GRADUAÇÃO E PESQUISA EM GEOGRAFIA (ENANPEGE), 9. 2011, Goiânia-GO. Anais... 2011.

GRAFF, V. D. ; SOUZA, E. B. C. O fenômeno urbano na região Costa Oeste do Paraná. In: ENCONTRO NACIONAL DE GEÓGRAFOS (ENG), 16, 2010, Porto Alegre. Anais... 2010.

GREGORY, V. Os eurobrasileiros e o espaço colonial: migrações no Oeste do Paraná (1940-1970). Cascavel: Edunioeste, 2002. 360 p.

HECK, F. M.; CARVALHAL, M. D. A territorialização do frigorífico de aves da Copagril em MCR (PR): precarização do trabalho e desrespeito à legislação trabalhista. Pegada, v.11, n. 2, dez. 2010. 
INSTITUTO BRASILEIRO DE GEOGRAFIA E ESTATÍSTICA - IBGE. Censo demográfico 2010. Disponível em: <www.ibge.gov.br>. Acesso em: 10 fev. 2011.

Atlas geográfico escolar. Rio de Janeiro, 2004.

IPARDES - INSTITUTO PARANAENSE DE DESENVOLVIMENTO ECONÔMICO E SOCIAL. Disponível em: <http:/ / Ipardes.gov.br>. Acesso em: 30 jan. 2011.

Oeste Paranaense: $3^{\circ}$ espaço relevante - especificidades e diversidades. Curitiba: IPARDES, 2008.

INDÚSTRIAS DO EXTREMO OESTE DO PARANÁ - INDEXOPAR. Portal das indústrias do extremo Oeste do Paraná. Disponível em: <http://www.indexopar.com.br>. Acesso em: 15 jun. 2011.

ITAIPU BINACIONAL. Disponível em: <htpp://www.itaipu.gov.br>. Acesso em: 20 ago. 2011.

LEFEBVRE, H. Direito à cidade. São Paulo: Centauro, 2001.

LIMONAD, E. Brasil século XXI, Regionalizar para que? Para quem? In: ; HAESBAERT, R; MOREIRA, R (Orgs.). Brasil século XXI por uma nova regionalização: agentes, processos e escalas. São Paulo: Lomonad, 2004. p. 54-66.

MACHADO, L. O. et al. Bases de uma política integrada de desenvolvimento regional para a Faixa de Fronteira. Brasília: Ministério da Integração Nacional, v.1. 2005, 450 p.

PERIS, A. F. (Org.). Estratégias de desenvolvimento regional: Região Oeste do Paraná. Cascavel: EDUNIOESTE, 2003. 536 p.

PERROUX, F. A economia do século XX. São Paulo: Heder, 1961.

PERROUX, F. O conceito de pólo de crescimento". In: FAISSOL, Esperidião (Org.). Urbanização e regionalização. Secretaria de Planejamento da Presidência da República, IBGE, 1975, p. 99-110.

PIFFER, Moacir. Apontamentos sobre a base econômica da região Oeste do Paraná. In: CASSIMIRO FILHO, F.; SHIKIDA, P. F. (Orgs.). Agronegócio e desenvolvimento regional. Cascavel; Edunioeste, 1999. p.57-84.

PIQUET, R. Cidade-empresa: presença na paisagem urbana brasileira. Rio de Janeiro: Jorge Zahar Editor, 1998.

PROGRAMA de Desenvolvimento da Faixa de Fronteira investe R 1,9 milhões no desenvolvimento regional. Disponível em: <http://www.integração.gov.br/comunicação/ notícias/noticia.asp?id=3075>. Acesso em: 17 mar. 2009.

QUATRO décadas de desenvolvimento - a evolução econômica e social dos municípios e localidades onde a Copagril se insere. Revista Copagril, Marechal Cândido Rondon (PR). Ano 6, n. 62, p.17, maio/jun. 2011.

REOLON, C. A. A aglomeração urbana da soja: um estudo sobre a gênese de aglomerações urbans nãometropolitans no Brasil. In: SIMPÓSIO NACIONAL DE GEOGRAFIA URBANA - SIMPURB, Anais... 29/10 a 2/11/2007, Florianópolis-SC.

SANTOS, M. Metamorfoses do espaço habitado: fundamentos teórico e metodológico da geografia. São Paulo: Hucitec, 1988.

A natureza do espaço: técnica e tempo, razão e emoção. São Paulo: Hucitec, 1996.

SOUZA, E. B. C. Estado: produção da região do Lago de Itaipu - turismo e crise energética. Tese de Doutorado. Presidente Prudente, SP: UNESP, 2002.

Políticas territoriais de desenvolvimento regional: o planejamento em foco nas margens do Lago de

Itaipu - Costa Oeste do Paraná. Revista Paranaense de Desenvolvimento, Curitiba: Ipardes, n.115, p.125147, jul./dez. 2008. 
A (re)produção da região do Lago de Itaipu. Cascavel: Edunioeste, 2009a, 222 p.

Tríplice Fronteira: fluxos da região Oeste do Paraná com o Paraguai e Argentina. Revista Terr@ Plural, v. 3, n. 1, p. 103-116, jan./jul. 2009b.

; GEMELLI, V. Território, região e fronteira: análise geográfica integrada da fronteira Brasil / Paraguai. In: XIV ENCONTRO NACIONAL DA ANPUR (ASSOCIAÇÃO NACIONAL DE PÓSGRADUAÇÃO E PESQUISA EM PLANEJAMENTO URBANO E REGIONAL), 14. Rio de Janeiro, 2011. Anais... Rio de Janeiro, 2011.

STERCHILE, S. P. W.; SOUZA, E. B. C. Apontamentos sobre a aplicação dos royalties da Itaipu Binacional e o processo de desenvolvimento. Revista Brasileira de Gestão e Desenvolvimento Regional. Taubaté: UNITAN, v. 4, n. 2, p. 3-22, maio/ago. 2008.

TOURINHO, A. de O. Centro e centralidade: uma questão recente. In: CARLOS, A. F.; OLIVEIRA, A. U. (Orgs.). Geografia de São Paulo. São Paulo: Hucitec, 2005. p. 277-299.

Recebido em 12/02/2012

Aceito para publicação em 29/03/2012 